\title{
Reports of work related musculoskeletal injury among home care service workers compared with nursery school workers and the general population of employed women in Sweden
}

\author{
Yuichiro Ono, Monica Lagerström, Mats Hagberg, Arvid Lindén, Birgitta Malker
}

\begin{abstract}
Objectives-To describe the nationwide occurrence of work related musculoskeletal injuries among all home care service workers in Sweden, and to identify relative risks and risk factors of the injuries.

Methods-The study was based on work related injuries reported to the Swedish occupational injury information system in 1990-1. The work related musculoskeletal injuries were divided into overexertion accidents and musculoskeletal diseases. The incidence of the injuries in female home care service workers was compared with those in nursery school workers and all other employed women in Sweden.
\end{abstract}

Results-In home care service workers, the annual incidence of injury from overexertion accidents and musculoskeletal diseases were $19 \cdot 2$ and $15 \cdot 1$ per 1000 workers, respectively, which was higher than those in nursery school workers and all employed women in Sweden. For five injury locations including the back, all the age standardised relative risks (SRR) of overexertion accidents exceeded $4 \cdot 0$, and most of those for musculoskeletal diseases were 1.5 or more in home care service workers compared with all other employed women in Sweden. Total duration of sick leave due to overexertion accidents was 7.7 times, and musculoskeletal diseases 3.5 times, longer than in nursery school workers. National loss due to sick leave resulting from only musculoskeletal injuries in home care service workers was about $8 \cdot 2 \%$ of the total work related sick leave in all employed women in Sweden, although the number of home care service workers represented only some $5 \%$ of this population. Lifting other people was most frequently reported as the main risk cause of overexertion accidents in both kinds of workers.

Conclusions-The results support the hypothesis that home care service workers have higher annual injury incidence of musculoskeletal injuries than nursery school workers due to physically stressful tasks that are far less common in nursery school workers.
(Occup Environ Med 1995;52:686-693)

Keywords: injury reports; musculoskeletal; home care

In many developed countries, the need for home care services is growing rapidly. Reasons for this growth include an increase in the number of elderly people and a general tendency of people to stay at home, which is partly related to the development of medical care and reduced institutionalisation in hospitals due to cost containment pressure. ${ }^{12}$ Many studies exist concerning the work related health risks associated with institutional health care, ${ }^{3-6}$ and detailed preventive measures at work sites have been documented or standardised. ${ }^{7-10}$ On the other hand, little work has been done on health problems in home care service workers, although work in the home is suspected to entail, as well as the same risks as institutional health care, extra burdens on workers, as the work environment is uncontrolled and less standardised. ${ }^{11}$

Recent research on work related risks associated with home health (medical) care indicates that back and other musculoskeletal accidents and diseases are common in home nursing staff. ${ }^{11-13}$ Similarly, home care service (non-medical) workers were recently found to have a higher prevalence of symptoms in the neck, shoulders, and low back than a control group. ${ }^{14}$ In Sweden, there are about 110000 home care service workers who often work in private homes. The magnitude of the risks and factors related to the cause of work related musculoskeletal accidents and diseases in these workers has not yet been clarified in that country.

Patient handling has been considered to be one of the main risk factors of musculoskeletal problems in nursing staff. ${ }^{6}{ }^{15-18}$ It is suspected that home care service workers would have similar musculoskeletal troubles for similar reasons. Thus, we suspected that nursery school workers would have musculoskeletal troubles associated with tasks such as lifting and carrying children. Their person handling loads, however, would be less stressful than those of home care service workers because the people in their care are healthier and smaller. Besides, home care service workers have other strenuous material handling tasks 
such as shopping, carrying, washing, cleaning, and cooking, which are far less common in nursery school workers. Thus, it was considered meaningful to compare the occurrence of musculoskeletal accidents and diseases between home care service workers and nursery school workers to estimate the differences in the effect of work loads upon the musculoskeletal system in the two occupations.

The aim of this investigation was to describe the nationwide occurrence of work related musculoskeletal reports of accidents and diseases in all home care service workers in the working population of Sweden, and to identify relative risks and factors related to the accidents and diseases by comparing home care service workers with nursery school workers and with all other employed women in Sweden.

\section{Subjects and methods} REPORTING SYSTEM

In Sweden the working population is compulsorily insured against work related accidents and diseases as well as against commuting accidents. According to Swedish law, the employers or self employed people must report all such accidents and diseases on an inquiry form that is sent to the labour inspectorate. The work injury insurance scheme presents a general description of what is to be considered as work related accidents and diseases, referring to those resulting from accidents and harmful influences at work. Besides accidents at work, the Work Injury Insurance Act describes examples of substances, energy radiation, strenuous work operations, working postures, pressure, vibrations, noise, temperatures, etc, in the category of work related accidents and diseases. General infectious conditions like colds are excluded.

The work related musculoskeletal injuries consist of overexertion accidents and musculoskeletal diseases. If accidents can be connected to a particular event or a specific point of time related to musculoskeletal overexertion at work like lifting a heavy object, it is classified as an overexertion accident. Other accidents like falls or vehicle accidents are not included in this category. Musculoskeletal diseases are disorders presumed to have developed after a long period of exposure to unfavourable ergonomic factors.

The work injury insurance compensates, in principle, for economic loss. Additional compensation for pain, incapacity, and other inconveniences can be obtained from funds based on collective agreements between employer organisations and trade unions. The number of reports of work related musculoskeletal injuries to the work injury insurance system is the subject of the present study, and the number of injuries additionally compensated by the funds on collective agreements are excluded. The information from the labour inspectorate is collected in the occupational injury information system that was instituted by the National Board of Occupational Safety and Health in 1979.
Occupational accidents involving at least one day of absence from work, and all work related diseases, are registered to form the official statistics of work related accidents and diseases produced by the occupational injury information system. The occupational injury information system coding is based on international classifications, including the international standard classification of occupation (ISCO) and the international standard classification of all economic activities (ISIC). There are also some individual occupational injury information system codes for activities, events, external agencies, and so on.

\section{STUDY BASE}

This study is based on work related overexertion accidents and musculoskeletal diseases reported to the occupational injury information system. All home care service workers (occupational code 154, ISCO 1958) with occurrence of work related overexertion accidents or diseases registered in the occupational injury information system in 1990 and 1991 were selected. The incidence of work related accidents and diseases in home care service workers was compared with that of nursery school workers (occupational code 153, ISCO 1958) and all other Swedish employed women. Men were excluded because of their very small numbers in home care service and nursery school workers. There were 105006 home care service workers and 108252 nursery school workers, representing $4.9 \%$ and $5.0 \%$, respectively, of the total population of employed women in Sweden. These figures are taken from the national population and housing census of people registered on 1 November $1990 . .^{19}$ Those working at least one hour a week on average during October 1990 were counted as gainfully employed workers in this census. We selected workers aged between 16 and 64 years.

\section{JOB DESCRIPTION}

Home care service workers care for the elderly or handicapped people in private or institutional homes. Their work comprises the care of the person, cooking, cleaning, necessary shopping errands, and washing. The care of the person involves dressing and undressing, bathing, hair washing, and visiting a doctor, all of which sometimes requires person handling tasks including lifting. Home care service workers periodically clean the living room, bedroom, kitchen, entrance, and washroom for the care client. When shopping, the home care service workers sometimes have to carry heavy bags of food and other domestic articles. Washing tasks include not only washing clothes but also ironing, folding and putting them away. In the census, $83 \%$ of home care service workers in Sweden work 20 or more hours a week.

In Sweden, nursery school workers take care of the children aged one to six years. There are two types of nursery school teachers; preschool teachers, qualified by professional education, and child minders. In this study, 
only child minders were chosen because their educational background as professionals was similar to home care service workers. Average incomes of the child minders and home care service workers are also very similar in Sweden. About $90 \%$ of nursery school workers in Sweden worked 20 or more hours a week. Their work comprises the care and educational activities for children-that is, meals, dressing and undressing, outings, play, painting, bathing, dancing, reading, and so forth. There are occasional person handling activities such as lifting and carrying children. The weights, sizes, and physical coordinative capacities of those receiving care, differ greatly from those of home care service workers. Nursery school workers usually take care of healthy children, whereas home care service workers often look after elderly people with impairment or clumsiness. In inspectional visits to more than 30 Swedish nursery schools, the authors found most of the chairs and tables for children were changed so as to match working heights. Supervisors in nursery schools also commonly educate workers to avoid unsuitable work postures. Therefore, it was thought unlikely that postural factors in person handling had a remarkable effect on musculoskeletal conditions in nursery school workers in Sweden. Thus, person handling tasks for nursery school workers are presumably physically less stressful than those for home care service workers. Besides, strenuous material handling tasks in home care service workers are far less common in nursery school workers, whose duties do not usually include lifting and carrying shopping materials, washing, cleaning, and cooking. In the job inspection and rough survey of social background, we did not find any evidence that the risks of musculoskeletal injuries in nursery school workers are greater than those in home care service workers.

\section{EPIDEMIOLOGICAL ANALYSES}

To determine the relative frequency of work related accidents and diseases, the annual injury incidence rate (AIIR)/1000 workers standardised to the age distribution of all employed women in Sweden in the census, was calculated as

$$
A I I R=1000 \Sigma 0.5 \star \frac{N_{1 i}}{N_{I T i}} \star \frac{N_{O i}}{N_{O T}}
$$

where $\mathbf{N}_{l i}=$ number of accidents and diseases in home care service workers in each age stratum, $\mathbf{N}_{1 T i}=$ total number of home care service workers in each age group, $\mathbf{N}_{o i}=$ number of all employed women in each age group, and $\mathrm{N}_{o T}=$ total number of all employed women. The multiplication by 0.5 in the expression was to obtain the average of the 1990 and 1991 rates. Age groups for calculation were 16-19, 20-24, 25-29, 30-34, 35-39, 40-44, 45-49, 50-54, 55-59, and 60-64 years. This formula was also applied to obtain the annual injury incidence rates for nursery school workers.

The age standardised relative risks (SRRs) of work related overexertion accidents and musculoskeletal diseases in home care service workers and nursery school workers compared with all other Swedish employed women were also calculated. This was done by subtracting the number of home care service workers and nursery school workers from the whole population of employed women in Sweden. Thus, the SRR is a ratio of two annual injury incidence rates-that is, directly age standardised rates. The SRR of the injuries between home care service workers and nursery school workers was also calculated, and the $95 \%$ confidence interval (95\% CI) for the SRR was computed by a logarithmic transformation. ${ }^{20}$ An age dependent trend in the proportion of injuries to workers was also tested by $\chi^{2}$ as proposed by Armitage. ${ }^{21}$

\section{Results}

OVEREXERTION ACCIDENTS IN ALL WORK

\section{RELATED ACCIDENTS}

The most common accidents were overexertion accidents related to exertion and falls in home care service workers, which were also most frequently found in nursery school workers (table 1). Vehicle accidents were the third most common events in home care service workers but the least in nursery school workers. The proportion of overexertion accidents $(61 \cdot 7 \%)$ to all work related accidents was significantly higher $\left(P<0.01\right.$ by $\chi^{2}$ test) in home care service workers than $(33.1 \%)$ in nursery school workers.

\section{MUSCULOSKELETAL DISEASES IN ALL WORK RELATED DISEASES}

The distribution of main factors leading to work related diseases was similar for home care service workers and nursery school workers (table 2). The most common disease was related to musculoskeletal exertion in home care service and nursery school workers. The second and third most common diseases were due to chemicals and social factors, which were far less frequent than musculoskeletal diseases.

Table 1 Reported main events and the annual injury incidence of work related accidents 1000 workers among home care service (HCS) and nursery school (NS) workers in Sweden (1990-1)

\begin{tabular}{lcc}
\hline & \multicolumn{2}{l}{ Occupations } \\
\cline { 2 - 3 } Events & HCS workers & NS workers \\
\hline Overexertion & $19 \cdot 2$ & 3.5 \\
Fall & 4.6 & 3.3 \\
Vehicle & 1.9 & 0.3 \\
Blow & 1.1 & 1.5 \\
Faulty step & 1.0 & 0.8 \\
Object rest & 0.9 & 0.6 \\
Object & 0.8 & 0.3 \\
Other & 1.2 & 0.7 \\
Total & 30.7 & 11.0 \\
\hline
\end{tabular}

Overexertion $=$ musculoskeletal accidents related to exertion fall $=$ fall on the same or to a lower level; vehicle $=$ accidents with vehicle in motion except for commuting accident; blow = blow, kick, or other contact with other person; faulty step = faulty steps or step on a nail; object rest = contact with object at rest; object = pressing, cutting, etc by handled object, 
Table 2 Reported main factors and the annual incidence of injury from work related diseases 1000 workers among home care service (HCS) and nursery school (NS) workers in Sweden (1990-1)

\begin{tabular}{lll}
\hline & \multicolumn{2}{l}{ Occupations } \\
\cline { 2 - 3 } Factors & HCS workers & NS workers \\
\hline Musculoskeletal & $15 \cdot 2$ & $6 \cdot 6$ \\
Chemical & $1 \cdot 8$ & $0 \cdot 7$ \\
Social & 0.9 & $0 \cdot 6$ \\
Infectious & $0 \cdot 2$ & $0 \cdot 2$ \\
Physical & $0 \cdot 1$ & $0 \cdot 1$ \\
Other & 0.3 & $0 \cdot 3$ \\
Total & 18.5 & 8.5 \\
\hline
\end{tabular}

Musculoskeletal $=$ musculoskeletal diseases related to exertion; chemical $=$ diseases related to chemical agents social = organisational and social factors; infectious = infectious agents; physical $=$ physical agents including vibration.

\section{ANNUAL INCIDENCE OF INJURY FROM} OVEREXERTION ACCIDENTS AND MUSCULOSKELETAL DISEASES

The annual incidence of injury from overexertion accidents and musculoskeletal diseases were much higher in home care service workers than in nursery school workers and the general population of all employed women (figs 1 and 2). With increasing age the annual incidence of injury from musculoskeletal diseases tended to increase in all groups, and this tendency was more pronounced in home care service and nursery school workers than that in the general population of all employed women. A significant increase in the proportion of overexertion accidents was found in the age group 25-54 in home care service and nursery school groups $\left(\chi^{2}=5.43 \mathrm{P}<0.05\right.$, $\chi^{2}=29.1 \mathrm{P}<0.01$, respectively, fig 1$)$. The annual incidence of injury from overexertion accidents was lowest in the 55-64 age group in home care service workers. The mean (SD) duration of employment in the present occu-

Figure 1 Annual incidence of injury (AII)/1000 workers due to overexertion accidents stratified by age. The age specific $A I I$ calculated as a mean in 1990-1 among home care service workers was compared with those among nursery school workers and the Swedish general population of all employed women.

Figure 2 Annual incidence of injury (AII)/1000 workers due to musculoskeletal diseases stratified by age. The age specific AII calculated as
an average in $1990-1$ among home care service workers was compared with those among nursery school workers and the Swedish general population of all employed women.
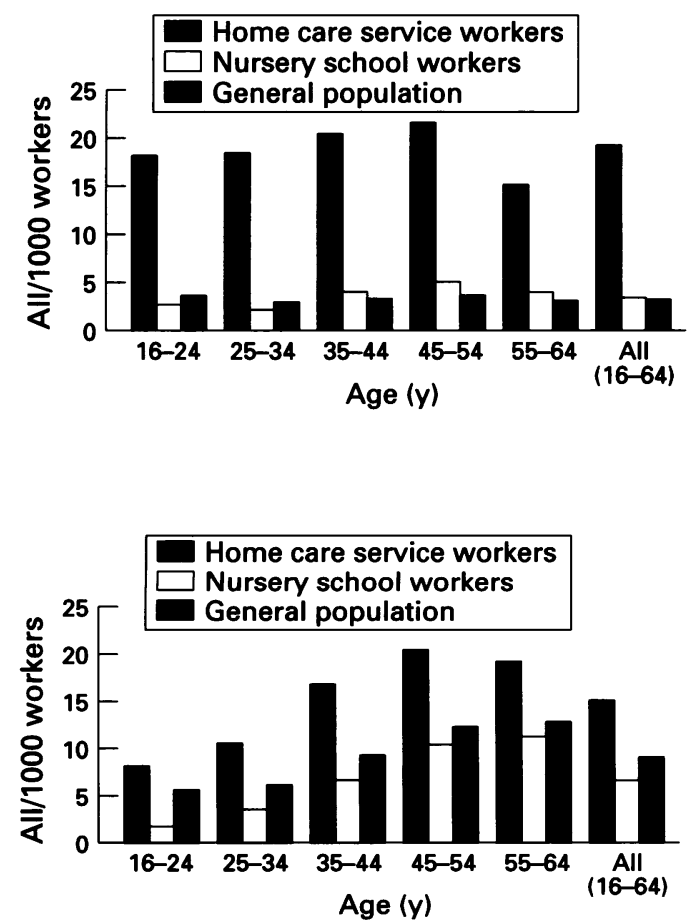

pation of home care service workers with musculoskeletal diseases was $11.5(7 \cdot 7)$ years, about three years longer than in home care service workers with overexertion accidents. In nursery school workers with musculoskeletal diseases, it was $12 \cdot 4(7 \cdot 5)$ years, about three years longer than in those with overexertion accidents.

In home care service workers the highest annual injury incidence rates of all overexertion accidents were found in the back $(11 \cdot 1)$, and in musculoskeletal diseases in the neck (5.0). This tendency was also seen in nursery school workers and the general population of all employed women. Relatively high annual incidence of injury in home care service workers were also noticed for the neck $(2 \cdot 7)$ and shoulder or arm (2.7) for overexertion accidents and for the back $(4 \cdot 0)$ and shoulder or arm (3.7) for musculoskeletal diseases.

\section{SRR OF OVEREXERTION ACCIDENTS AND}

MUSCULOSKELETAL DISEASES

With regard to five injury locations: the neck, back, hand or wrist, shoulder or arm, and leg or knee, all the SRRs of overexertion accidents exceeded 4.0 in home care service workers when compared with all other employed women in Sweden (table 3). The SRRs for the neck, shoulder or arm, and back were notably high (more than seven), whereas the SRRs of musculoskeletal diseases in home care service workers were $\mathbf{1 . 5}$ or more for all locations except the hand or wrist (table 3 ). For all overexertion accidents involving the five body parts the SRR (95\% CI) was $7 \cdot 7$ $(7 \cdot 4-8 \cdot 0)$ in home care service workers, and that for all diseases was $1 \cdot 7(1 \cdot 7-1 \cdot 8)$.

In nursery school workers, the SRR of overexertion accidents exceeded 1.0 only for the back (1.6) and leg or knee (1.9), and those of musculoskeletal diseases also slightly exceeded 1.0 only for the back and leg or knee (table 3). The SRR (95\% CI) in nursery school workers for all overexertion accidents involving the five locations was $1.4(1 \cdot 3-1 \cdot 5)$ $v 0.7(0.7-0.8)$ for all musculoskeletal diseases.

Table 3 Age SRRs (95\% CIs) of overexertion accidents and musculoskeletal diseases among home care service (HCS) and nursery school (NS) workers compared with the risks among the Swedish general population of all other employed women in 1990-1

\begin{tabular}{|c|c|c|c|}
\hline & HCS workers & \multicolumn{2}{|c|}{ NS workers } \\
\hline & $S R R(95 \% C I)$ & $S R R$ & $(95 \% C I)$ \\
\hline $\begin{array}{l}\text { overexertion accidents } \\
\text { Neck } \\
\text { Back } \\
\text { Hand or wrist } \\
\text { Shoulder or arm } \\
\text { Leg or knee } \\
\text { Total of five parts }\end{array}$ & $\begin{aligned} 10 \cdot 1 & (9 \cdot 1-11 \cdot 3) \\
7 \cdot 9 & (7 \cdot 5-8 \cdot 3) \\
4 \cdot 7 & (3 \cdot 8-5 \cdot 7) \\
8 \cdot 4 & (7 \cdot 6-9 \cdot 3) \\
4 \cdot 9 & (4 \cdot 3-5 \cdot 7) \\
7 \cdot 7 & (7 \cdot 4-8 \cdot 0)\end{aligned}$ & $\begin{array}{l}0.9 \\
1.6 \\
0.9 \\
1.0 \\
1.9 \\
1.4\end{array}$ & $\begin{array}{l}(0 \cdot 7-1 \cdot 2) \\
(1 \cdot 4-1 \cdot 7) \\
(0 \cdot 6-1 \cdot 5) \\
(0 \cdot 7-1 \cdot 3) \\
(1 \cdot 5-2 \cdot 4) \\
(1 \cdot 3-1 \cdot 5)\end{array}$ \\
\hline $\begin{array}{l}\text { Musculoskeletal diseas } \\
\text { Neck } \\
\text { Back } \\
\text { Hand or wrist } \\
\text { Shoulder or arm } \\
\text { Leg or knee } \\
\text { Total of five parts }\end{array}$ & $\begin{array}{ll}1.5 & (1 \cdot 4-1 \cdot 6) \\
2 \cdot 7 & (2 \cdot 5-2 \cdot 9) \\
0.9 & (0 \cdot 8-1 \cdot 0) \\
1.6 & (1 \cdot 5-1 \cdot 7) \\
2.5 & (2 \cdot 2-2 \cdot 8) \\
1.7 & (1 \cdot 7-1 \cdot 8)\end{array}$ & $\begin{array}{l}0.7 \\
1.2 \\
0 \cdot 3 \\
0.6 \\
1.3 \\
0.7\end{array}$ & $\begin{array}{l}(0.6-0 \cdot 7) \\
(1 \cdot 1-1 \cdot 4) \\
(0 \cdot 2-0 \cdot 4) \\
(0 \cdot 6-0 \cdot 7) \\
(1 \cdot 0-1 \cdot 6) \\
(0 \cdot 7-0.8)\end{array}$ \\
\hline
\end{tabular}


Table 4 Age SRRs (95\% CIs) of overexertion accidents and musculoskeletal diseases among home care service (HCS) workers compared with the risk among nursery school (NS) workers

\begin{tabular}{lrl}
\hline & $S R R$ & $(95 \% C I)$ \\
\hline Overexertion accidents: & & \\
Neck & $11 \cdot 4$ & $(8 \cdot 4-15 \cdot 4)$ \\
Back & $5 \cdot 1$ & $(4 \cdot 6-5 \cdot 7)$ \\
Hand or wrist & $5 \cdot 0$ & $(3 \cdot 1-8 \cdot 1)$ \\
Shoulder or arm & $8 \cdot 5$ & $(6 \cdot 4-11 \cdot 4)$ \\
Leg or knee & $2 \cdot 6$ & $(2 \cdot 0-3 \cdot 4)$ \\
Total of five parts & $5 \cdot 5$ & $(5 \cdot 1-6 \cdot 0)$ \\
Musculoskeletal diseases: & & \\
Neck & $2 \cdot 3$ & $(2 \cdot 0-2 \cdot 6)$ \\
Back & $2 \cdot 2$ & $(1 \cdot 9-2 \cdot 5)$ \\
Hand or wrist & $3 \cdot 2$ & $(2 \cdot 3-4 \cdot 5)$ \\
Shoulder or arm & $2 \cdot 4$ & $(2 \cdot 1-2 \cdot 8)$ \\
Leg or knee & $2 \cdot 0$ & $(1 \cdot 5-2 \cdot 6)$ \\
Total of five parts & $2 \cdot 3$ & $(2 \cdot 1-2 \cdot 5)$ \\
\hline
\end{tabular}

Figure 3 Average and total duration of sick leave due to overexertion accidents among home care service workers compared with those among nursery school workers in 1990-1.

Figure 4 Average and total duration of sick leave due to musculoskeletal diseases among home care service workers compared with those among nursery school workers in 1990-1.

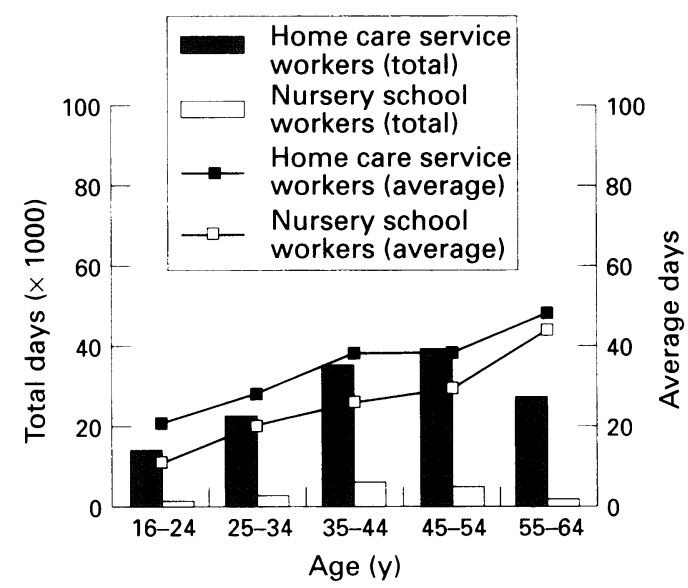

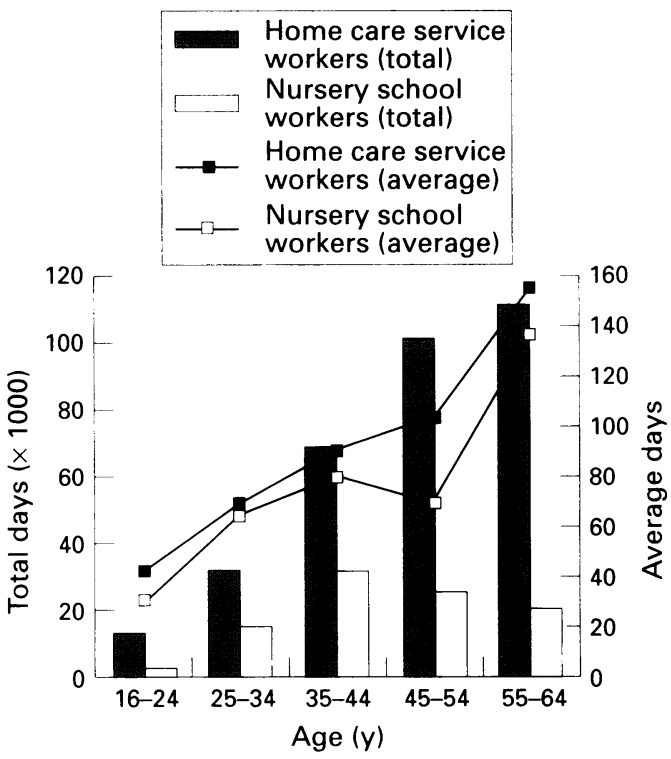

Numbers of people

$\begin{array}{lllllll}0 & 500 & 1000 & 1500 & 2000 & 2500 & 3000\end{array}$ Other person (handling) VIIIIIIIIIIIIIIIIIIIIIIIIIIIIIIIIIIIIIIA

Construction parts

Materials and goods Lifting machines or vehicles Handling tools or implements Air conditioning

Electrical equipment

Other converting machines

Other factors
The SRRs were higher for overexertion accidents than for musculoskeletal diseases in both home care service and nursery school workers. Comparison of overexertion accidents in home care service workers with nursery school workers showed that the SRRs were 5.0 or more for all locations except the leg or knee (table 4) $v 2.0$ or more for musculoskeletal diseases.

\section{SICK LEAVE}

In home care service workers, the mean and total duration of sick leave for overexertion accidents were 35.0 and 139633 days, respectively, and 101.6 and 325654 days for musculoskeletal diseases. With increasing age, the mean and total duration tended to increase notably in both overexertion accidents and musculoskeletal diseases except in the oldest age group for overexertion accidents (figs 3 and 4). The average and total duration of sick leave were $24 \cdot 8$ and 18235 days, respectively, for the overexertion accidents in nursery school workers, and 78.4 and 94377 days for the musculoskeletal diseases. With increasing age of nursery school workers, the average duration tended to increase, whereas total duration was greatest in the 3544 age group (figs 3 and 4 ).

Thus, total duration of sick leave due to overexertion accidents was $7 \cdot 7$ and due to musculoskeletal diseases was 3.5 times greater in home care service workers than in nursery school workers. Total loss due to sick leave resulting from overexertion accidents and musculoskeletal diseases was nearly 465000 days in home care service workers in 1990-1. This figure corresponded to about $8 \cdot 2 \%$ of all work related sick leave days (5 655000 days) including all types of accident and disease in all employed women in Sweden in 1990-1.

\section{MAIN RISK FACTOR}

The factors registered as having a primary relation to the reported cause of overexertion accidents were classified in two different ways - that is, classification by the type of objects being handled and by activities involving lifting or other exertion. In home care service workers, handling another person was most frequently reported $(n=3009,75 \cdot 7 \%)$ to be the main risk factor, other factors representing only some $25 \%(n=967)$ of all reports (fig 5$)$. In the activities classification, lifting represented $81 \cdot 2 \%(n=3229)$ of all reports and $94 \cdot 7 \%(\mathrm{n}=2851)$ of those involved handling another person. In nursery school workers, handling of another person was also most frequently reported ( $n=412,56.5 \%$ ) to be the main risk factor and $88 \cdot 1 \%(n=363)$ of the tasks were also related to lifting activities.

Person handling accounted for $55 \cdot 1 \%(\mathrm{n}=$ 1766) of the main risk factors for the musculoskeletal diseases in home care service workers, and $79.5 \%(n=957)$ of those in nursery school workers. Risk factors remained unknown in $29.2 \%$ of musculoskeletal diseases in home care service workers and $11 \cdot 2 \%$ of those in nursery school workers. 


\section{Discussion}

IMPORTANCE OF OVEREXERTION ACCIDENTS AND MUSCULOSKELETAL DISEASES IN HOME CARE SERVICE AND NURSERY SCHOOL WORKERS The annual incidence of injury and SRRs of overexertion accidents and musculoskeletal diseases were notably higher in home care service workers than in the general population of all other employed women in Sweden. This was found not only for the back, but also the neck, shoulder or arm, hand or wrist, and leg or knee-that is, high risk locations. The annual incidence of injury from back accidents was higher than that in nurses' aides (8.92) in a study by Engkvist et al..$^{22}$ Johansson reported high odds ratios (ORs, 1.39-1.52) for symptoms in the neck, shoulders, and low back in home care service workers compared with a control group of office workers, teachers, child care workers, and others. ${ }^{14}$ These results accord with those in our study, but our data showed higher levels.

The annual incidence of injury and SRRs of overexertion accidents and musculoskeletal diseases were higher in home care service workers than in nursery school workers. This supports our hypothesis that incidences of overexertion accidents and musculoskeletal diseases would be higher in home care service workers than in nursery school workers. Home care service workers will have to perform more stressful person and material handling tasks such as care of the elderly, shopping and carrying, washing, cleaning, and cooking jobs that are far less common in nursery school workers. It should be noted that the lower limit of the $95 \%$ CI of SRRs was greater than 1.0 for accidents to the back and leg or knee, and back diseases in nursery school workers. Some studies showed that the neck, shoulders, arms, and back were high risk locations for work related musculoskeletal problems in nursery school workers in Japan. ${ }^{23-26}$ In the occupational injury information system in Sweden, however, we found that SRRs were less than 1.0 for the neck and shoulder and arms in nursery school workers. There have been no international comparative studies on working conditions and work load of nursery school workers. Thus, the reasons for this discrepancy in the results of investigations conducted in two countries should be the subject of future studies.

National loss due to sick leave resulting from overexertion accidents and musculoskeletal diseases accounted for about $8 \cdot 2 \%$ of all work related sick leave in all Swedish working women, although the number of home care service workers represented only some $5 \%$ of this population. Thus, it is considered important and urgent for the national economy to decrease work related overexertion accidents and musculoskeletal diseases in home care service workers.

Relative risks of neck accidents and diseases were as high as those of back accidents and diseases in Swedish home care service workers. Mäkelä et al studied a representative population sample of 8000 people in Finland and reported that ORs for chronic neck pain syndrome were increased by some determinants such as physical and mental stress at work, and the neck pain syndrome was also closely associated with low back pain. ${ }^{27}$ Linton also reported that lifting and uncomfortable work posture were found to increase the risk of both neck and back pain problems in the questionnaire study of more than 20000 Swedish workers. ${ }^{28}$ Thus, the high risks of neck problems in home care service workers do not seem to be unusual, although the biological mechanism relating neck symptoms to back problems remains unclear.

\section{EFFECT OF AGE}

The annual incidence of injury from overexertion accidents and musculoskeletal diseases tended to increase with the age of home care service workers. In general this would be partially attributed to pathological changes in the musculoskeletal system or decreases in muscular strength and other physical capability due to aging. ${ }^{29}$ There must be more factors aggravating musculoskeletal conditions of home care service and nursery school workers than in the general population, because we found a more prominent age dependent increase in home care service and nursery school workers. As person handling is one of their routine tasks, home care service and nursery school workers need more physical strength than some other workers do. Hence it is supposed that the effect of work load on the musculoskeletal system would be more significant in home care service and nursery school workers than in other occupations if their capabilities are reduced by aging. Preventive measures, including decrease of work load corresponding to the age of the workers, would be essential especially for home care service and nursery school workers.

The lowest annual incidence of injury from overexertion accidents was found in the 55-64 age group in home care service workers. In Sweden, early retirement in this age group was not uncommon. ${ }^{30}$ In the 1989 statistics, the number of early retirements per 1000 people was 174.0 in the 55-59 age group and 330.4 in the $60-64$ group, but less than 100 in every other five year age group. Aronsson et al reported that newly retired people with early retirement pensions had higher complaint scores of back, shoulder, and arm pain than did those with retirement due to maturation of age. ${ }^{31}$ In another study of Finnish workers representative of the general labour force over 35 years of age, the most common ground for early retirement, especially in older workers, was the fear of losing, or the loss of, their health and working capacity. ${ }^{32}$ Thus, it is suspected that the annual incidence of injury in the oldest age group in Sweden at least could be largely biased by much early retirement and does not reflect the real situation in this group.

\section{RISK FACTORS}

Studies on the relation of patient handling tasks to episodes of back pain, overexertion accidents, and musculoskeletal diseases sup- 
port the notion that person handling tasks can be the main risk factors of overexertion accidents and musculoskeletal diseases in home care service workers. ${ }^{6}{ }^{15-18}$ Recent studies also suggest risk factors of musculoskeletal problems in home care service workers. Johansson reported that the prevalence of musculoskeletal symptoms in home care service workers was associated with both psychosocial factors and physical work load. ${ }^{14}$ In his questionnaire study, psychosocial factors consisted of supervisory attitude, influence on and control of work, stimulus from the work, relations with fellow workers, and psychological work load. $\mathrm{He}$ also included some physical work load (lifting, repetitive and monotonous movement, unsuitable postures, trunk flexion, and hands above shoulder height). In the report on home care service workers by Aronsson et $a l$, early retirement pensioners had high scores for musculoskeletal symptoms and complaints of working conditions before retirement, including difficulty in walking and shopping, uncomfortable work position, work under time pressure, and effort to keep up. ${ }^{31}$ Torgén et al studied the work load of nursing aides in the home care services and reported that they spent most of their working day walking or standing, which could be very tiring for the back and feet. ${ }^{33}$ These authors also reported that the amount of the day spent in poor back postures and time spent on cleaning tasks correlated positively to perceived exertion and to sick leave. As the work of home care service workers contains tasks resembling those of nursing aides, similar physical strain could cause their musculoskeletal problems.

The mean duration of employment in the present occupation was 11.5 years in home care service workers with musculoskeletal diseases, and about three years longer than that in those with overexertion accidents in our study. This may imply the long term cumulative effects of many risk factors on the development of musculoskeletal diseases. There is no information on the weekly working hours of home care service workers with musculoskeletal injuries registered in the occupational injury information system. The number of past occurrences of the diseases was also unavailable in the occupational injury information system, making it impossible to determine whether the reported injuries had occurred for the first time or not. Thus, we were unable to work out cumulative working hours from the beginning of employment to the first occurrence of musculoskeletal diseases. We think that the occupational injury information system should have some additional variables to increase its use for epidemiological studies, including working hours of the reported cases and the number of the past occurrence of the injuries.

In our study, the main risk factor reported to the occupational injury information system was person handling in home care service workers, which is accompanied not only by lifting activity but also trunk flexion and unsuitable postures. The studies already mentioned suggested many other factors that influence musculoskeletal conditions of home care service workers. ${ }^{14} 3133$ Besides, our study only dealt with limited factors reported to have a primary relation with musculoskeletal injuries and no information was available as to the extent to which other factors might contribute to the development of injuries. Considering the many risk factors for musculoskeletal injuries and the highly variable nature of the work, the data and studies remain insufficient to reach any definite conclusion about risk factors in home care service workers. Thus, field studies on work load and epidemiological investigations with temporal design for analysing causes of many factors, are necessary in the future.

\section{EXTRAPOLATION TO OTHER COUNTRIES}

It might be supposed that relative risks of musculoskeletal injuries are similarly high in home care service workers in other developed countries if they have analogous strenuous tasks in their work. International comparison of the Swedish statistics may be almost impossible for work related injuries because criteria for work related injuries vary widely from country to country. In Japan, for example, the number of musculoskeletal diseases without accidental origin treated according to injury compensation law for workers is less than $2 \%$ of that reported in the occupational injury information system in Sweden. ${ }^{19} 34$

\section{POSSIBLE BIAS}

There are some studies on underreporting to the occupational injury information system. ${ }^{35-37}$ Larsson et al made a comparative study of work related accidents in three different registries-that is, hospital and insurance registries, and the occupational injury information system in the municipality of Umeå. ${ }^{35}$ They found that $27 \%$ of cases that should legally have been reported to the occupational injury information system were missing. Engkvist et al also reported that the incidence of low back accidents estimated in their questionnaire study was 20 times higher than reported in the occupational injury information system for workers in a nursing district. ${ }^{37}$ Thus, the actual numbers of accidents and diseases could be far greater than the annual incidence of injury based on the occupational injury information system, although the occupational injury information system may reflect more severe cases than the study population data, which is based on complaints only.

As the occupational injury information system is based on reports from employers that are often initiated by workers, motives for registration could be biased in some occupational sectors by psychosocial factors, including union activities, workers' knowledge of work related accidents and diseases, and relations between labour and management. Reporting of work related accidents and diseases is strongly urged by law in all occupational sectors in Sweden, and therefore these differences in reporting attitudes might not be very large in various occupations. To our knowledge, we are not aware of any major con- 
founders in home care service and nursery school workers that could have influenced the reporting to the occupational injury information system. This reporting issue requires further study.

In accidents, risk factors are usually registered as events when they have just occurred. In general, the records seem to be reliable because accidental events often occur so noticeably as to be observed by other workers. On the other hand, in musculoskeletal disease the onset is usually unclear and records of risk factors are inevitably considered speculative and anecdotal. This may partially explain why nearly $30 \%$ of the records lacked any description of risk factors. Although acknowledging this drawback, it should nevertheless be noted that person handling tasks were indicated as a risk factor in more than half of the records of musculoskeletal diseases.

\section{Conclusions}

Statistics show that national loss due to musculoskeletal injuries has been extremely high in Sweden. Thus, it is considered important and urgent for the Swedish national economy that the number and severity of these injuries be reduced in home care service workers. The present results clearly support the hypothesis that home care service workers have higher annual incidence of injury from musculoskeletal injuries than nursery school workers due to physically stressful tasks that are far less common in nursery school workers.

1 American Medical Association Council on Scientific Affairs. Council report, home care in the 1990s. $\mathscr{F A M A}$ 1990;263:1241-4.

2 Swedish National Board of Occupational Health Ordinance on care and assistance in private homes. Arbetarskyddssamling författningssamling 1990;18:1992. (In Swedish.)

3 Magora A, Taustein I. An investigation of the problem of sick-leave in the patient suffering from low back pain. Ind Med 1969;38:80-90.

4 Klein BP, Jensen RC, Sanderson LM. Assessment of workers' compensation claims for back strains/sprains. workers' compensation claim
f Occup Med $1984 ; 26: 443-8$.

5 Marchette L, Marchette B. Back injury: a preventable occupational hazard. Orthopaedic Nursing 1985;4:25-9.

6 Harber P, Elizabeth B, Gutowski M, SooHoo K, Lew M Roman A. Occupational low-back pain in hospital nurses. F Occup Med 1985;27:518-24

7 Standards Association of Australia. Guide to the lifting and moving of patients. Part $1-$ Safe manual lifting and moving of patients. North Sydney: Standards Association of Australia Standards House, 1982. (Australian Standard 2569.)

8 Stubbs DA, Baty D, Buckle PW, Fernandes AF, Hudson MP, Rivers PM, et al. Back pain in nurses, summary and recommendations. Surrey: University of Surrey, 1986 .

9 Lloyd P, Tarling C, Troup JDG, Wright B, Charlesworth D. The handling of patients. 2nd ed. Middlesex: Back Pain Association. London: Royal College of Nursing, 1987

10 Stockholm County Council. The Stockholm training concept. Stockholm: Stockholm City Council,1987. In Swedish.)

11 Smith AW, White MC. Home health care, occupational health issues. American Association of Occupational Health Nurses fournal 1993;41:180-5.

12 Knibbe J, Friele RD. Back pain and patient lifting in nurses working in home care. In: Hagberg $M$, Hofmann F, Stößel U, Westlander G, eds. Occupational health for health care workers: proceedings of the 1st international coalth care workers: proceedings of the 1st international congress on occupational health for health care workers;
September 1992. Landsberg: Ecomed verlagsgesellschaft September 1992. Land

13 Toomingas A. The health situation among Swedish health care workers. Occupational health for health care workers. In: Hagberg M, Hofmann F, Stößel U, Westlander G, eds. Occupational health for health care workers: proceedings of the 1st international congress on occupational health for health care workers; September 1992. Landsberg: Ecomed verlagsgesellschaft $\mathrm{mbH}, 1993: 37-42$.

14 Johansson $J \AA$. Psychosocial factors, physical load, and symptoms from the neck, shoulders and back among
home care workers. In: Hagberg M, Hofmann F, Stößel U, Westlander G, eds. Occupational health for health care workers: proceedings of the 1st international congress on occupational health for health care workers; September 1992. Landsberg: Ecomed verlagsgesellschaft $\mathrm{mbH}$, 1993:326-31

15 Harber P, Elizabeth B, Vojtecky M, Rosenthal E, Shimozaki S, Horan M. Nurses' beliefs about cause and prevention of occupational back pain. $\mathcal{F}$ Occup Med 1988;30:797-800.

16 Lortie M. Analyse comparative des accidents déclarés par des préposés hommes et femmes d'un hôpital gériades preposes hommes et femmes d'un hopital géria-
trique. Fournal of Occupational Accidents 1987;9:59-81. trique. Fournal of Occupational Accid

17 Owen BD. The need for application of ergonomic principles in nursing. In: Asfour SS, ed. Trends in ergonomics/ human factors $I V$. New York: Elsevier, 1987:831-8.

18 Videman T, Rauhala $H$, Asp S, Lindström K, Cedercreutz $\mathrm{G}, \mathrm{Kämppi} \mathrm{M}$, et al. Patient-handling skill, back injuries, and back pain. An intervention study in nursing. Spine 1989;14:148-56.

19 Official Statistics of Sweden, National Board of Occupational Safety and Health, Statistics Sweden. Occupational risks 1990-1991, occupational accidents and diseases. Stockholm: Svenskt Tryck AB, 1994. (In diseases. Stockholm: Svenskt Try

20 Ahlbom A. Biostatistics for epidemiologists. Boca Raton: Lewis, 1993

21 Armitage $P$. Tests for linear trends in proportions and frequencies. Biometrics 1955;11:375-86.

22 Engkvist I-L, Hagberg M, Lindén A, Malker B. Over-exertion back accidents among nurses' aides in Sweden. Safety Science 1992;15:97-108.

23 Nagira T, Suzuki J, Oze Y, Ohara H, Aoyama $H$. Cervicobrachial and low-back disorders among school lunch workers and nursery-school teachers in comparison with cash-register operators. $\mathcal{F} \mathrm{Hum}$ Ergol (Tokyo) 1981;10:117-24.

24 Kurumatani N, Iki M, Katagi K. A study on occupational cervicobrachial disorder (OCD) of nursery school teachcervicobrachial disorder (OCD) of nursery school teach-
ers based on subjective symptoms related to OCD. fapanese fournal of Industrial Health 1984;26:389-96. (In Japanese with English abstract, figures, and tables.)

25 Ono Y, Hosokawa M, Maeda K, Miyao M. 1987. Occupational cervicobrachial disorders (OCD) and associated back pain in Japan. In: Osterholz U, Karmaus W, Hullmann B, Ritz B, eds. Work-related musculoskeletal disorders: proceedings of an international symposium; fune 1985. Bonn: Wirtschaftsverlag NW, 1987:279-305.

26 Ono Y, Shimaoka M, Hiruta S, Shibata E, Huang J, Takeuchi Y, et al. Analysis of ergonomic problems in the work at nursery schools. Nagoya $¥$ Health Physical Fitness and Sports 1990;13:91-100. (In Japanese with English and Sports 1990;13:91-100.

27 Mäkelä M, Heliövaara M, Sievers $K$, Impivaara $O$, Knekt $P$, Aromaa A. Prevalence, determinants, and consequences of chronic neck pain in Finland. Am $\mathcal{f}$ Epidemiol 1991;134:1356-67.

28 Linton SJ. Risk factors for neck and back pain in a working population in Sweden. Work and Stress 1990;4:41-9.

29 Parker KG, Imbus HR. Cumulative trauma disorders. Chelsea, MI: Lewis, 1992.

30 Westerholm $P$, Baltzari $L$. The social security systems in Sweden and its utilisation by the elderly work force. In: Kilbom $\AA$, ed. Early retirement and social security systems. Kilbom A, ed. Early retirement and social security systems. the situation of workers in Denmark, Finland, Norway, and
Sweden. Arbete och Hälsa 1992:29. Solna: National Sweden. Arbete och Hälsa 1992:29. Solna:
Institute of Occupational Health, 1992:39-59.

31 Aronsson G, Astvik W, Thulin A-B. Working conditions and occupational exclusion among home care workers in Stockholm. A comparison between a group of care givers on early retirement/disablement pensions and a group of healthy, now retired care givers. Arbete och Hälsa 1993:26. Solna: National Institute of Occupational Health, 1993. In Swedish with English summary.)

32 Huuhtanen $P$, Piispa $M$. Work or retirement: alternatives of elderly people in the 1990s. In: Kilbom A, ed. Early retirement and social security systems. The situation of workers in Denmark, Finland, Norway and Sweden. Arbete och
Hälsa 1992:29. Solna: National Institute of Occupational Health, 1992:60-6.

33 Torgén M, Nygård C-H, Käll C, Kilbom A. Physiological strain and its relation to work tasks and physical capacity among elderly nursing aides in home care service. Proceedings of 24th congress of the international commission on occupational health; September 1993. Nice: ICOH, 1993:282.

34 Japanese Association of Public Health Statistics. The trend of national health. 1993. (In Japanese.)

35 Larsson T, Björnstig U. The epidemiology of occupational accidents: three ways to measure the problem in a Swedish municipality. Fournal of Occupational Health and Safety of Australia and New Zealand 1990;6:39-52.

36 Jacobsson B, Schelp L. One-year incidence of occupational injuries among teenagers in a Swedish rural tional injuries among teenagers in a Swe
municipality. Scand $\mathcal{F}$ Soc Med 1988;16:21-5.

37 Engkvist IL, Wigaeus Hjelm E, Hagberg M, Olivius G, Hellström S. Musculoskeletal accidents at work and free time among health care workers. Proceedings of the 48th time among health care workers. Proceedings of the 48th 1991 Nov; Stockholm. Stockholm: Swedish Society of Medicine 1991. (In Swedish.) 